\title{
Lentibulariaceae do Parque Nacional do Itatiaia, Brasil
}

\author{
Lentibulariaceae from the Itatiaia National Park, Brazil
}

\author{
Hugo Dolsan de Freitas ${ }^{1,3}$, Paulo Cesar Baleeiro ${ }^{2}$ \& Marcelo Trovó $^{1}$
}

\begin{abstract}
Resumo
Lentibulariaceae é cosmopolita e possui três gêneros, Genlisea, Pinguicula e Utricularia, com cerca de 29, 100 e 220 espécies, respectivamente. O Parque Nacional do Itatiaia possui relevo bastante acidentado, onde encontram-se muitas nascentes de rios, lagos e uma grande diversidade de bromélias. Assim, sua vegetação e seus ambientes são habitats propícios para a ocorrência de espécies de Lentibulariaceae. Os estudos sobre estas espécies no local são, todavia, escassos e restritos a antigas listagens de espécies. Apresentamos aqui o tratamento florístico completo para as Lentibulariaceae do Parque Nacional do Itatiaia. Foram registradas oito espécies, todas pertencentes ao gênero Utricularia. As espécies foram encontradas ocorrendo em corpos d'água da parte alta do parque, sendo que somente $U$. reniformis ocorre também nos riachos da parte baixa do parque. É apresentada uma chave de identificação para as espécies ocorrentes, além de descrições detalhadas de cada espécie, comentários e fotografias. Palavras-chave: flora, carnívoras, Serra da Mantiqueira, taxonomia, Utricularia.
\end{abstract}

\begin{abstract}
Lentibulariaceae is cosmopolitan, composed of three genera, Genlisea, Pinguicula, and Utricularia, containing ca. of 29, 100, and 220 species, respectively. The Itatiaia National Park is an elevated area with many rising rivers, lakes, wet places, and bromeliads. Therefore, it is promising to the occurrence of Lentibulariaceae species. However, studies in Lentibulariaceae in the area are scarce, restricted to a few old species lists. We present here the floristic treatment of the family in the Itatiaia National Park. Eight species were recorded, all belonging to Utricularia. All species occur in wet places of the Itatiaia Plateau, and only U. reniformis also occurs in the rivers of non-elevated areas. An identification key to the species, detailed descriptions, comments, and photos are provided. Key words: flora, carnivorous, Serra da Mantiqueira, taxonomy, Utricularia.
\end{abstract}

\section{Introdução}

Lentibulariaceae é cosmopolita e possui três gêneros, Genlisea A. St.-Hil. com 29 espécies, Pinguicula L. com cerca de 100 espécies e Utricularia L., o maior gênero da família, com cerca 220 espécies (Taylor 1989; Fleischmann 2012). Na América do Sul são encontradas 95 espécies nativas de Utricularia, das quais 82 ocorrem no Brasil e 26 são endêmicas deste país (Taylor 1989; BFG 2015). Genlisea possui distribuição na África, América Central e do Sul. No Brasil ocorrem 17 espécies distribuídas por quase todo o território nacional, sendo que 10 espécies são endêmicas do país (Fromm-Trinta 1979; Fleischmann 2012; BFG 2015). Pinguicula ocorre em quase todos os continentes, exceto na Antártida e na Austrália, porém não ocorre no Brasil (Casper 1996; Blanca et al. 1999).

Após a descrição original de Utricularia, mais de 900 novos táxons foram incluídos no gênero. Taylor (1989) propôs que mais de $3 / 4$ das espécies descritas eram sinônimos, reconhecendo em sua monografia 214 espécies. O gênero é composto por ervas exclusivamente carnívoras, anuais ou perenes, e são encontradas em diversos ambientes. Podem ser terrícolas, litófitas, reófitas, epífitas, ou aquáticas, ocorrendo desde locais arenosos a pantanosos. Tem como habitats principais locais com disponibilidade de água corrente, ou depósitos temporários de água, tais como poças, lagos e rios (Taylor 1989).

\footnotetext{
${ }^{1}$ Universidade Federal do Rio de Janeiro, Lab. Integrado de Sistemática Vegetal, Depto. Botânica, Inst. Biologia, Av. Carlos Chagas Filho 373, 21941-590, Rio de Janeiro, RJ, Brasil. hugodolsan@gmail.com,martrovo@gmail.com

${ }^{2}$ Universidade de São Paulo, Lab. Sistemática Vegetal, Depto. Botânica, Inst. Biociências, R. do Matão 277, 05508-900, São Paulo, SP, Brasil. paulobaleeiro@gmail.com

${ }^{3}$ Autor para correspondência: hugodolsan@gmail.com
} 
O Parque Nacional do Itatiaia é a primeira unidade de conservação do Brasil (Aximoff \& Ribeiro 2012). Nele, encontram-se espécies de Utricularia distribuídas em toda sua extensão, sendo que a maioria destas parece ser mais frequente na parte alta, em especial no planalto do Itatiaia (Aximoff \& Ribeiro 2012). Até o momento existe apenas um trabalho preliminar das Lentibulariaceae do Itatiaia (Barroso 1957), que cita apenas três espécies, ou trabalhos mais completos em áreas adjacentes ou similares ao Parque Nacional do Itatiaia. Nos campos rupestres, especificamente na Cadeia do Espinhaço, há estudos realizados acerca das Lentibulariaceae na Serra do Cabral, em Grão Mogol e na Serra do Cipó, revelando uma grande diversidade (Fromm-Trinta 1996; Fromm-Trinta 2004). Na Serra da Mantiqueira, os levantamentos no Parque Estadual do Ibitipoca e na Serra de São José são os único tratamentos florísticos completos para a família (Silva et al. 2011; Andrade \& Forzza 2012). Além destes trabalhos, as Lentibulariaceae figuram em listas florísticas em áreas de relevante diversidade (Salimena et al. 2013).

Sendo de suma importância o aumento do conhecimento sobre as Lentibulariaceae na região da Serra da Mantiqueira, em especial em seu maciço central, este trabalho tem como principal objetivo realizar o tratamento florístico das espécies que ocorrem no Parque Nacional do Itatiaia. É apresentada uma chave para identificação, além de um detalhamento sobre a morfologia e distribuição geográfica das espécies que ocorrem nesta unidade de conservação.

\section{Material e Métodos}

O Parque Nacional do Itatiaia foi criado em junho de 1937 e fica situado na Serra da Mantiqueira. Abrange os municípios de Itatiaia e Resende no estado do Rio de Janeiro e Bocaina de Minas e Itamonte no estado de Minas Gerais. Está entre as latitudes $22^{\circ} 19^{\prime}$ e $22^{\circ} 45^{\prime} \mathrm{S}$ e longitudes $44^{\circ} 45^{\prime}$ e $44^{\circ} 50^{\prime} \mathrm{W}$, possui altitude variando entre $700 \mathrm{~m}$ e $2.787 \mathrm{~m}$ e ocupa atualmente cerca de 30.000 ha. O Parque abrange a parte mais elevada da Serra da Mantiqueira, tendo como ponto culminante o Pico das Agulhas Negras com 2.787 $\mathrm{m}$. A maior parte da área pertence ao estado do Rio de Janeiro, e o restante a Minas Gerais, estendendose na direção oeste até a divisa de São Paulo (Pádua \& Coimbra-Filho 1979; Câmara 1991).

O relevo do Parque Nacional do Itatiaia é montanhoso, incluindo encostas e o topo do planalto, onde emergem notáveis penhascos rochosos. Predominam as rochas nefelíticas, alcalinas e de origem eruptiva que formaram-se no Jurássico (Pádua \& Coimbra-Filho 1979). A vegetação que recobre a Serra da Mantiqueira na região do Parque Nacional do Itatiaia é um remanescente único na paisagem do vale do rio Paraíba. As variações altitudinais permitem que sejam encontradas desde formações florestais densas até campos de altitude (Pádua \& CoimbraFilho 1979; Câmara 1991).

As coletas foram realizadas em toda a extensão do Parque Nacional do Itatiaia entre 2012 e 2015. Todo o material coletado foi preservado segundo técnicas usuais em taxonomia vegetal. Alguns espécimes foram trazidos para cultivo no Jardim Botânico do Rio de Janeiro. As exsicatas foram depositadas no herbário da Universidade Federal do Rio de Janeiro (RFA) e do Jardim Botânico do Rio de Janeiro (RB). Foram realizadas visitas aos seguintes herbários: GUA, HB, HUMC, R, RB, RFA, SPF. Todo material foi identificado até o nível específico e as análises e descrições morfológicas foram realizadas em estereomicroscópio utilizando-se a terminologia encontrada em Taylor (1989). Não foram encontrados espécimes em fruto e portanto os mesmo não foram descritos neste trabalho.

\section{Resultados e Discussão}

Foram registradas oito espécies, todas pertencentes ao gênero Utricularia. As espécies foram encontradas ocorrendo em corpos d'água da parte alta do parque, sendo que somente $U$. reniformis ocorre também na parte baixa do parque. Utricularia subulata representa uma nova ocorrência para o parque. O presente trabalho registra cinco espécies a mais que o tratamento inicial para a família (Barroso 1957), além de atualizar os nomes previamente citados.

Andrade \& Forzza (2012) encontraram 10 espécies de Utricularia e duas de Genlisea no tratamento das Lentibulariaceae do Parque Estadual do Ibitipoca. Já Silva et al. (2011) registraram 10 espécies de Utricularia e três de Genlisea na flora de Lentibulariaceae da Serra de São José. Essa maior diversidade de gêneros e espécies nestas duas áreas pode ser explicada em parte pela influência de áreas de cerrado adjacentes ao maciço do Ibitipoca e da Serra de São José. Pode ser resultando também do fato de que estas regiões possuem solos com maior presença de quartzo, ambiente favorável a ocorrência de espécies de Lentibulariaceae e mais raro em no Parque Nacional do Itatiaia. 


\section{Chave de identificação para as espécies de Lentibulariaceae do Parque Nacional do Itatiaia}

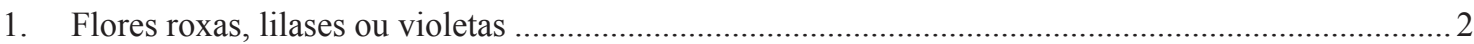

2. Folhas peltadas, com presença de mucilagem .......................................4. Utricularia pubescens

2'. Folhas não peltadas e sem mucilagem .................................................................................. 3

3. Bractéolas conadas à bráctea até próximo ao meio, lábio inferior da corola amplamente obovado com ápice formando lobos semelhantes ............................................................. 4

4. Lábio inferior da corola com ápice crenado................................. . Utricularia tricolor

4'. Lábio inferior da corola com ápice distintamente 3-lobado..... 8. Utricularia tridentata

3'. Bractéolas e bráctea livres, lábio inferior da corola transversalmente oblongo com lobo mediano menor que os laterais ou quase inconspícuo

5. Folhas reniformes

5. Utricularia reniformis

5'. Folhas elípticas a cordadas

1. Utricularia geminiloba

1'. Flores amarelas

3. Utricularia praelonga

6. Bractéolas presentes, brácteas laciniadas

6'. Bractéolas ausentes, brácteas inteiras 7

7. Brácteas basolutas (peltada)

6. Utricularia subulata

7'. Brácteas basifixas

2. Utricularia gibba

1. Utricularia geminiloba Benj. Fl. Bras. 10: 242. 1847.

Fig. 1a,b

Erva terrícola ou litófita; folhas verdes, dimórficas, glabras, coriáceas, elípticas a cordadas, base cuneada a cordiforme, ápice arredondado a agudo ou acuminado, 3,5-10 × 2-5 cm, pecíolo ca. $5 \mathrm{~cm}$ compr.; ou glabras, membranáceas, circulares a elípticas, base obtusa, ápice arredondado 1-4 mm compr.; inflorescência ereta, simples, 3-6 flores; escapo terete, $20-50 \mathrm{~cm}$ compr., glabro, verde; escamas monomórficas, basifixas, lanceoladas, margem inteira, ápice acuminado 3-5 cm compr.; brácteas basifixas, lanceoladas ou ovadas a subuladas, ápice acuminado, margem inteira, 5-8 $\mathrm{mm}$ compr.; bractéolas presentes, fusionadas na base, similares às brácteas, mais estreitas e curtas; cálice com lobos similares, glabros, estreito-ovados, 5-9 mm compr., margem inteira, ápice acuminado ou agudo; corola violeta com mancha amarela na giba, glabra; lábio superior ovado a oblongo, ápice arredondado, 5-10 mm compr., maior que o cálice; lábio inferior transversalmente oblongo, $1-2 \times 2,5$ $\mathrm{cm}$, base gibosa arredondada, bilobada, rugoso no ápice da giba; ápice 3-lobado, lobo mediano deltoide ou inconspícuo, reduzido em relação aos lobos laterais obovados distintamente maiores; calcar com mesmo comprimento do lábio inferior, ca. $1 \mathrm{~cm}$ compr., cilíndrico, ápice agudo, curvado para cima. Material examinado selecionado: Itatiaia, III.1937, A.C. Brade 15643 (R, RB); II.1894, E. Ule 1575 (R).

Material adicional examinado: Teresópolis: XII.1996 P. Occhioni 2050 (RFA); s.d., R.S. Couto 318 (RFA); s.d., A. Guedes 1 (RFA).
Utricularia geminiloba é uma espécie endêmica do Brasil, ocorrendo apenas nos estados do Rio de Janeiro e São Paulo (Taylor 1989; BFG 2015). Habita afloramentos rochosos úmidos, às vezes pedras verticais e pântanos com Sphagnum. Diferencia-se das outras espécies, principalmente de $U$. reniformis, pela forma de suas folhas: $U$. reniformis possui folhas reniformes e $U$. geminiloba possui folhas elípticas ou cordiformes. O nome U. itatiaiae Taub., citado em Barroso (1957), está hoje na sinonímia de $U$. geminiloba (Taylor 1989; BFG 2015). Encontrada com flores nos primeiros meses do ano.

2. Utricularia gibba L. Sp. Pl. 1: 18. 1753.

Fig. 1c

Erva aquática ou semiaquática; folhas verdes, translúcidas, monomórficas, levemente glandulosas, membranáceas, filiformes, base truncada fundida ao estolão, ápice atenuado. 3-6 mm compr., não pecioladas, mas ramificadas dicotomicamente até 5 vezes, por vezes uma dicotomia substituída por um utrículo; inflorescência ereta, simples, 1-3 flores; escapo terete, 15-36 cm compr., glabro, verde; escamas monomórficas, basifixas, depresso-ovadas a transversalmente oblongas, margem lisa, ápice arredondado e/ou ondulado, $1 \mathrm{~mm}$ compr.; bráctea semelhante às escamas; bractéolas ausentes; cálice com lobos similares, glabros, largo-elípticos, 2,5-10 $\mathrm{mm}$ compr., margem inteira e ápice ondulado, corola amarela, levemente pilosa, giba com muitas nervuras amarronzadas, lábio superior rômbico, ápice arredondado a emarginado, 3-8 mm compr., 

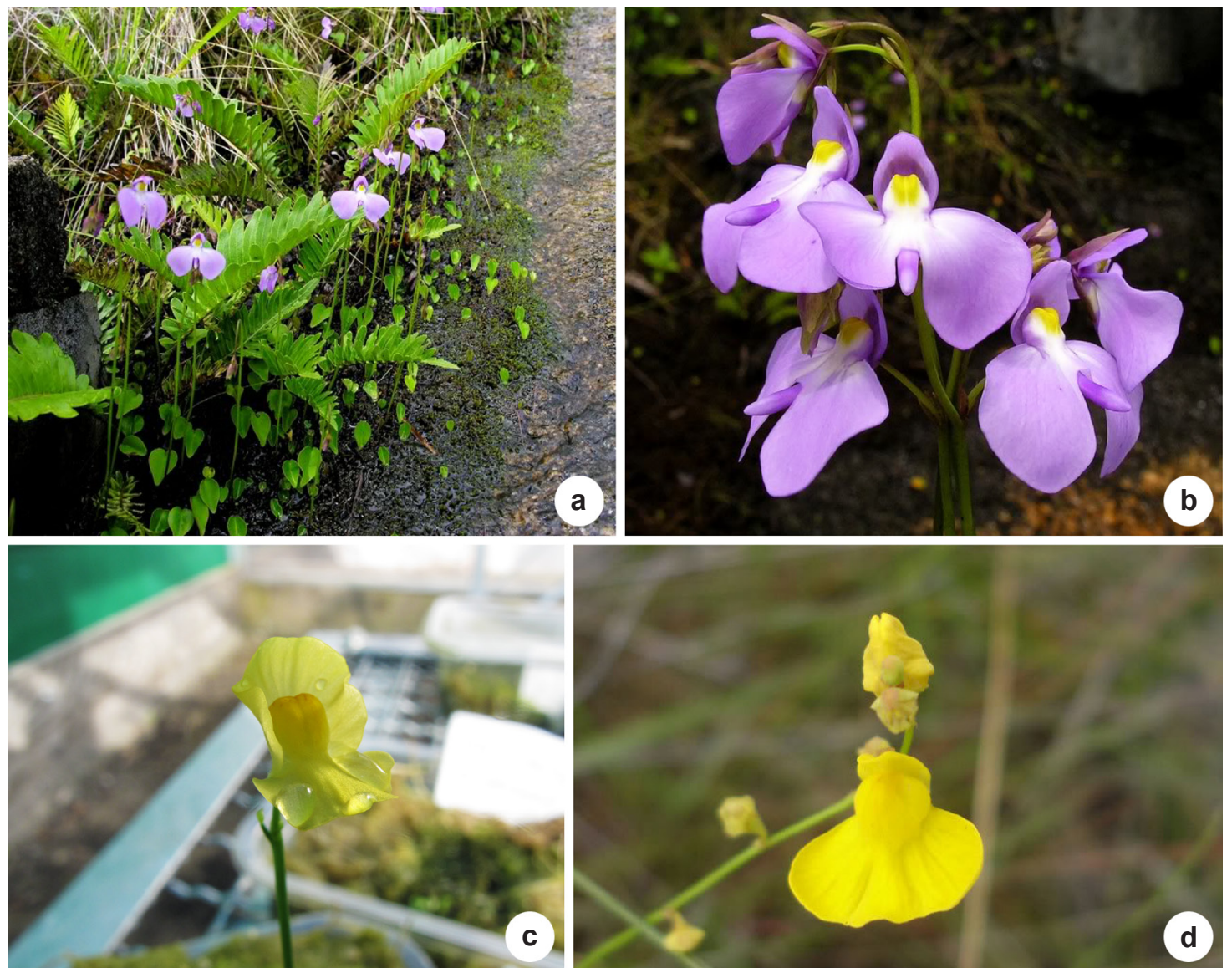

d

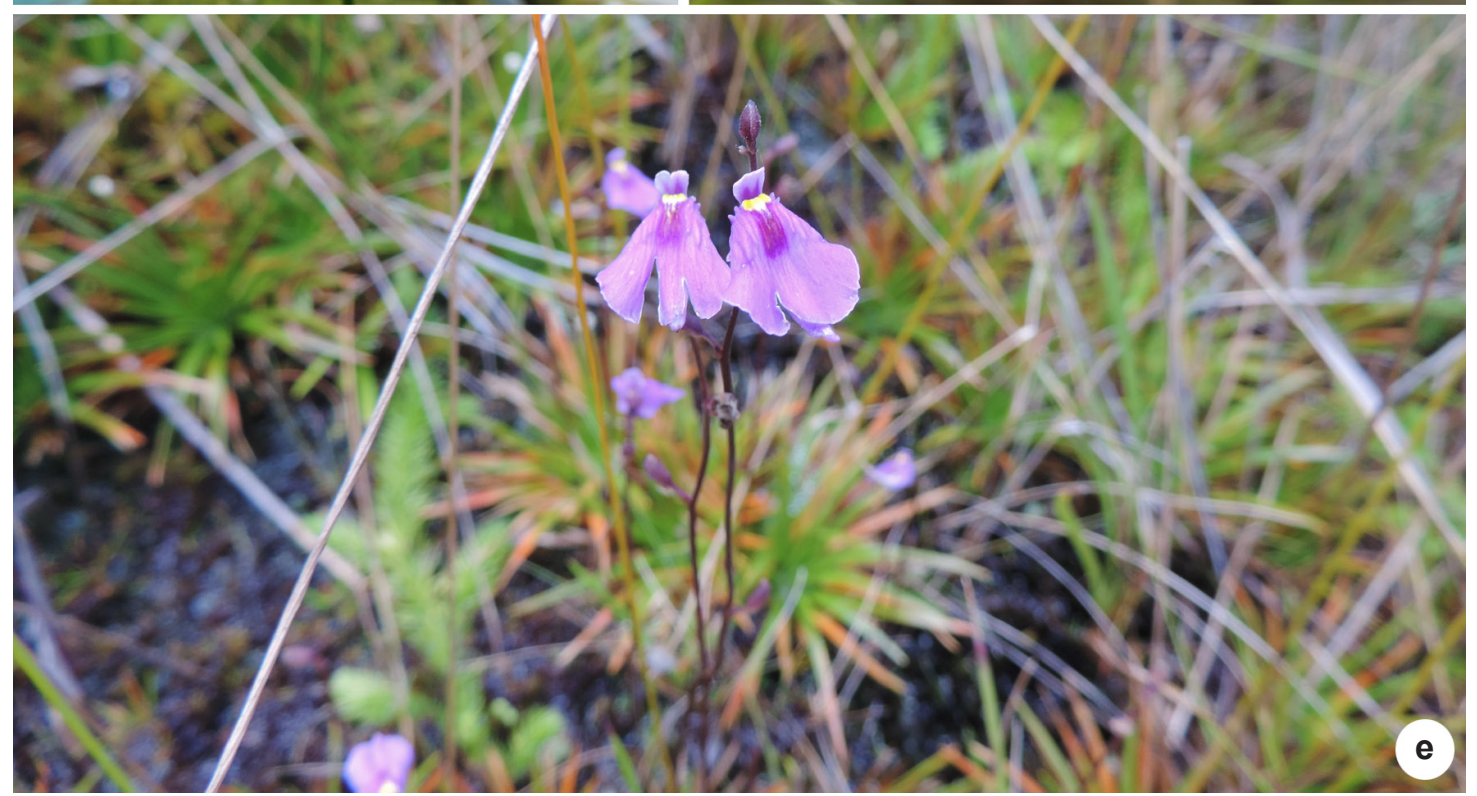

Figura 1 - Espécies de Lentibulariaceae do Parque Nacional do Itatiaia, Rio de Janeiro (Brasil) - a-b. Utricularia geminiloba; c. Utricularia gibba; d. Utricularia praelonga; e. Utricularia pubescens. Barras: a $=5 \mathrm{~cm} ; \mathrm{b}=1,5 \mathrm{~cm}$; $\mathrm{c}=0,5 \mathrm{~cm} ; \mathrm{d}=1 \mathrm{~cm} ; \mathrm{e}=0,5 \mathrm{~cm}$. (fotos: a-b. Fernando Rivadavia; c,e. Hugo Dolsan; d. Paulo Minatel Gonella). Figure 1 - Lentibulariaceae species from the Itatiaia National Park, Rio de Janeiro (Brazil) - a-b. Utricularia geminiloba; c. Utricularia gibba; d. Utricularia praelonga; e. Utricularia pubescens. Scale bars: $\mathrm{a}=5 \mathrm{~cm} ; \mathrm{b}=1.5 \mathrm{~cm} ; \mathrm{c}=0.5 \mathrm{~cm} ; \mathrm{d}=1 \mathrm{~cm} ; \mathrm{e}=0.5 \mathrm{~cm}$. (photos: a-b. Fernando Rivadavia; c,e. Hugo Dolsan; d. Paulo Minatel Gonella). 
maior que o cálice; lábio inferior rômbico, ca. $8 \times$ $4 \mathrm{~mm}$, base truncada, ápice obovado, obscuramente 3-lobado, lobos similares; calcar do mesmo comprimento ou ligeiramente maior que o lábio inferior, ca. $1 \mathrm{~cm}$ compr., cônico ou sacóide, ápice bifurcado ou não.

Material examinado selecionado: Itatiaia, III.1937, A.C. Brade 14644 (RB); 22.II.1947, B. Lute 13032 (R); XII.1903, C. Moreira 42 (R); 7.VI.1947, F.S. Vianna 758 (RFA); 23.II.2015 H. Dolsan \& M. Trovó 7 (RFA). Material adicional examinado: PARÁ: Carajás, 2005 F.A. Esteves 33 (RFA); PARANÁ: Piraquara, 4.X.2012, R.C. Forzza 7317 (RB); RIO DE JANEIRO: Nova Friburgo, III.1937, P. Occhioni 7678; Teresópolis, s.d., P. Occhioni 8776 (RFA).

Utricularia gibba tem distribuição Pantropical. No Brasil ocorre desde a Amazônia até o Rio Grande do Sul, com exceção de alguns estados do Norte (Taylor 1989; BFG 2015). Habita lagos, locais com água corrente bem lenta e pântanos (Taylor 1989). No parque foi encontrada em lagoas do planalto de Itatiaia. Além de aquática, $U$. gibba diferencia-se de U. subulata e $U$. praelonga pela ausência de bractéolas, e presença de folhas filiformes dicotomicamente ramificadas portando utrículos. Floresce no Parque Nacional do Itatiaia durante o ano todo, mas principalmente entre os meses de novembro e fevereiro.

3. Utricularia praelonga A.St.-Hil. \& Girard Ann. Sci. Nat., Bot. 11: 161. 1839.

Fig. 1d

Erva terrícola; folhas verdes, trimórficas, glabras, cartáceas, espatulada, base obovada, ápice acuminado, ca. $7 \times 3 \mathrm{~mm}$, pecíolo ca. $3 \mathrm{~cm}$ compr.; lanceolada, ca. $3 \times 0,5 \mathrm{~cm}$, pecíolo ca. 3 cm compr.; lineares, ca. $7 \times 0,3 \mathrm{~cm}$ compr., pecíolo ca. $4 \mathrm{~cm}$ compr.; inflorescência ereta, simples, 3-8 flores; escapo terete, 7-12 cm compr., glabro a esparsamente híspido na base, verde; escamas monomórficas, basifixas, lanceoladas, margem levemente laciniada, ápice acuminado, 3-5 mm compr.; brácteas basifixas, oblanceoladas a obovadas, margem laciniada, ápice irregular, ca. 2 $\times 1 \mathrm{~mm}$; bractéolas presentes, fusionadas na base, subuladas a lineares, margem levemente laciniadas; cálice com lobos desiguais, lábio superior maior que o inferior, glabros, largo elípticos, ca. $3 \mathrm{~mm}$ compr., margem denteada, ápice acuminado; corola amarela, glabra, lábio superior ovado, ápice arredondado, ca. $1 \times 0,5 \mathrm{~cm}$, maior que o cálice; lábio inferior elíptico, 1,5-3 × $1 \mathrm{~cm}, 3$-lobado, lobos laterais ligeiramente maiores e central praticamente inconspícuo, ápice emarginado; calcar maior ou com o mesmo comprimento do lábio inferior, ca. 1 cm compr., cônico, ápice agudo, levemente curvo.

Material examinado selecionado: Itatiaia, 15.X.1992, J.G. Kuhlman (RB326499).

Material adicional selecionado: MINAS GERAIS: Lima Duarte, 5.II.2004, R.C. Forzza et al. 2658 (RB); 18.I.2005, R.C. Forzza et al. 3915 (RB); São Roque de Minas, 20.XI.2007 R. Mello-Silva 3065 (RB); Serra do Cipó, 08.III.2009 D.C. Zappi 1868 (RB); PARANÁ: Recanto das Araucárias, s.d., C. Dudziak 37 (R).

Utricularia praelonga possui distribuição restrita à América do Sul, ocorrendo no Brasil, Paraguai e Argentina. No Brasil, ocorre nos estados de Tocantins, Bahia, Goiás, Minas Gerais, Rio de Janeiro, São Paulo, Paraná, Santa Catarina e Rio Grande do Sul (BFG 2015). Habita os campos naturais alagados, florestas de galeria e brejos, ocorrendo preferencialmente em altitudes que variam entre 750 e 1500 metros. No Itatiaia a espécie é encontrada na parte alta do parque. Utricularia praelonga diferencia-se das demais espécies do parque pela bráctea basifixa laciniada evidente, com lacínios vináceos, acompanhadas por duas bractéolas subuladas a lineares, sépalas desiguais com margens denteadas e folhas simples trimórficas. Taylor (1989) descreve as folhas de $U$. praelonga como dimórficas, no material do Parque Nacional de Itatiaia é encontrada uma terceira variação, com lamina lanceolada, assim como em Andrade \& Forzza (2012). O material proveniente de Itatiaia possui escapos mais curtos que o padrão da espécies. Foi coletada com flores em outubro.

4. Utricularia pubescens Sm. in Rees, Cycl. xxxvii. n. 53.1818.

Fig. 1e

Erva terrícola; folhas verdes, monomórficas, glabras a glandulosas, membranáceas, peltadas, ca. $5 \mathrm{~mm}$ diam., pecíolo ca. $2 \mathrm{~mm}$ compr.; inflorescência ereta, simples, 1-5 flores; escapo terete, 20-40 cm compr., glabro a levemente setuloso, marromarroxeado; escamas monomórficas, basifixas, estreito-truladas, margem lisa nas laterais e denteada a aculeada no ápice, ápice agudo, ca. 1 mm compr.; brácteas basolutas, fixadas próximas a base, lanceoladas, ápice agudo, margem inteira, ca. $2 \mathrm{~mm}$ compr.; bractéolas presentes, livres, similares às brácteas, mais estreitas e menores; cálice com lobos similares, ligeiramente glabros, pubescentes ou setulosos, ca. $4 \times 4 \mathrm{~mm}$, lábio superior ovado, ápice obtuso, agudo ou acuminado, lábio inferior ovado, arredondado, margem denteada a aculeada no ápice, lisa nas laterais, ápice agudo; corola roxa com uma mácula amarela esbranquiçada e uma faixa roxa mais escura no lábio inferior, 
glabra; lábio superior oblongo, ápice arredondado levemente curvado para a frente, ca. 2,5 × $\mathrm{mm}$, maior que o cálice; lábio inferior obovado, ca. $11 \times$ $7 \mathrm{~mm}$, ápice arredondado; calcar ligeiramente maior que o lábio inferior da corola ca. $5 \mathrm{~mm}$ compr., cilíndrico, ápice bífido, reto ou pouco curvado.

Material examinado selecionado: Itatiaia, 2.III.1921, P.C. Porto 997 (RB); 26.II.1936, A.C. Brade 15145 (RB); 1937, A.C. Brade 1564 (RB); 8.III.1945, F.S. Vianna 770 (RFA); 1.VII.1950, A.C. Brade 20226 (RB); 23.II.2015, H. Dolsan \& M. Trovó 6 (RFA).

Utricularia pubescens ocorre na Índia, África e Américas do Sul e Central. No Brasil é registrada em Roraima, Amazonas, Ceará, Mato Grosso, Goiás, Minas Gerais, Rio de Janeiro, e São Paulo (Taylor 1989; BFG 2015). Habita solos pantanosos, rochas úmidas, ocorrendo em áreas abertas ou sombreadas, desde o nível do mar, até 1900 m alt. (Taylor 1989). No Parque Nacional do Itatiaia, foi encontrada ocorrendo próxima a córregos em solo pantanoso, arenoso ou ainda em meio a aglomerados de Sphagnum decomposto na parte alta do parque. Pode ser facilmente diferenciada por suas folhas peltadas orbiculares com mucilagem em sua superfície e, eventualmente, tricomas simples no cálice, bráctea, bractéolas e pedicelo. Os materiais coletados no Parque Nacional do Itatiaia possuem escapos longos para o padrão da espécie. Floresce no Parque Nacional do Itatiaia entre os meses de novembro e março.

5. Utricularia reniformis A.St.-Hil., Voy. Rio de Janeiro \& Minas Gerais 1: 244. 1830. Fig. 2a,b

Erva terrícola ou epífita; folhas verdes, ou avermelhadas na face abaxial, monomórficas, glabras a pubescentes, membranosas, reniformes, 3-12 × 3-8 cm, pecíolo 7-27 cm compr.; inflorescência ereta, simples, 2-5 flores; escapo terete, 30-40 cm compr., glabro, verde ou marrom; escamas monomórficas, basifixas, estreitoelípticas, margem lisa, ápice arredondado, $3 \times 1$ $\mathrm{mm}$; brácteas basifixas, oblanceoladas, ápice agudo a obtuso, margem lisa, 3-5 mm compr.; bractéolas presentes, livres, basifixas, estreito elípticas, margem inteira; cálice com lobos desiguais, glabros, 8-18 mm compr., margem inteira, lobo superior oval lanceolado, base ovada, lobo inferior oval, ligeiramente menor; corola lilás, glabra, giba com duas listras verticais amarelas envoltas em uma mancha violeta; lábio superior ovado, ápice arredondado, 1-2 cm compr., maior que o cálice; lábio inferior transversalmente oblongo, 2-3 $\times 3$ $\mathrm{cm}, 3$-lobado, ápice arredondado, lobos laterais redondos e bem maiores, lobo mediano inconspícuo ou reduzido; calcar ligeiramente maior que o lábio inferior, ca. $2 \mathrm{~cm}$ compr., estreitamente cilíndrico, ápice ligeiramente acuminado, pouco curvo a reto. Material examinado selecionado: Itatiaia, 12.III.1947, P. Occhioni 948 (RFA); 7.VI.1947, F.S. Vianna 758 (RFA); 3.XII.1996, S.J. Silva Neto 754 (RB); 14.XI.2014, H. Dolsan \& M. Trovó 2 (RFA); 15.11.2014, H. Dolsan \& M. Trovó 3 (RFA).

Material adicional selecionado: ESPÍRITO SANTO: Alto Caparaó: 9.XII.1917, A. Lutz 123 (R).

Utricularia reniformis é endêmica do Brasil, de distribuição em todos os estados das regiões Sudeste e Sul (BFG 2015). Está presente em locais com abundância de água, ocorrendo geralmente diretamente na rocha ou em solos arenosos. No Parque Nacional do Itatiaia a espécie pode ser encontrada próxima aos corpos d'água. Utricularia reniformis apresenta uma grande variação no tamanho e formato de suas estruturas vegetativas, podendo em alguns casos ser confundida com $U$. nelumbifolia Gardner. Pode ser diferenciada de $U$. nelumbifolia e das demais espécies que ocorrem no Parque por suas folhas reniformes e também por suas grandes e vistosas flores. Floresce no Parque Nacional do Itatiaia durante o ano todo, mas principalmente entre novembro e fevereiro.

\section{Utricularia subulata L. Sp. P1. 1: 18. 1753.}

Fig. 2c

Erva terrícola; folhas verdes, monomórficas, glabras, membranáceas, filiformes, base e ápice arredondado, ca. 2 cm compr., não peciolada; inflorescência ereta, simples, 1-2 flores; escapo terete, ca. $17 \mathrm{~mm}$ compr., densamente glanduloso e papiloso na base, marrom claro e verde; escamas dimórficas, basolutas, rômbicas, margem ciliada, ápice agudo, ca. 1,5 mm compr.; ou basolutas na porção mediana do escapo, rômbicas, margem inteira, ápice acuminado, ca. 1,2 mm compr.; brácteas presentes, basolutas, amplexicaule, rômbicas, extremidades arredondadas, ápice truncado, margem lisa, ca. 1,5 mm compr.; bractéolas ausentes; cálice com lobos pouco diferenciados, glabros, ovados a circulares, 1-2 mm compr., margem inteira, ápice arredondado; corola amarela, glabra; lábio superior ovado a oblongo, ápice irregularmente arredondado, ca. 1,3 mm compr., maior que o cálice; lábio inferior arredondado a rômbico, ca. $4 \times 5 \mathrm{~mm}$, ápice 3-lobado, lobos laterais quase iguais ao lobo mediano, arredondados, lobo mediano mais alongado, oblongo; calcar maior que o lábio 

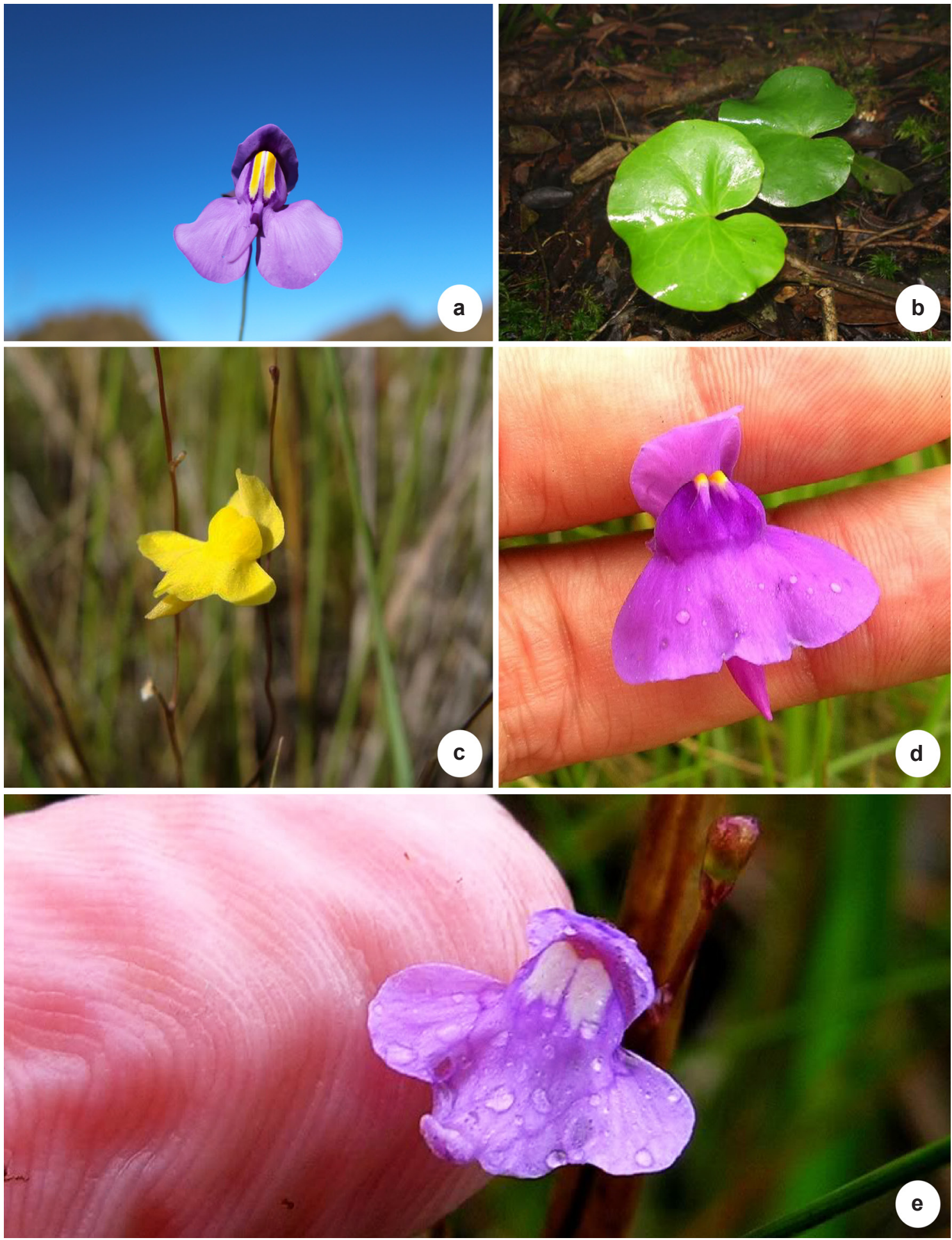

Figura 2 - Espécies de Lentibulariaceae do Parque Nacional do Itatiaia, Rio de Janeiro (Brasil) - a-b. Utricularia reniformis; c. Utricularia subulata; d. Utricularia tricolor; e. Utricularia tridentata. Barras de escala: $\mathrm{a}=1,5 \mathrm{~cm} ; \mathrm{b}=3$ $\mathrm{cm} ; \mathrm{c}=0,2 \mathrm{~cm} ; \mathrm{d}=0,5 \mathrm{~cm} ; \mathrm{e}=0,1 \mathrm{~cm}$. (fotos: a. Marcelo Trovó; b. Paulo Minatel Gonella; c-e. Fernando Rivadavia). Figure 2 - Lentibulariaceae species from the Itatiaia National Park, Rio de Janeiro (Brazil) - a-b. Utricularia reniformis; c. Utricularia subulata; d. Utricularia tricolor; e. Utricularia tridentata. Scale bars: a $=1.5 \mathrm{~cm} ; \mathrm{b}=3 \mathrm{~cm} ; \mathrm{c}=0.2 \mathrm{~cm} ; \mathrm{d}=0.5 \mathrm{~cm} ; \mathrm{e}=0.1 \mathrm{~cm}$. (photos: a. Marcelo Trovó; b. Paulo Minatel Gonella; c-e. Fernando Rivadavia). 
inferior, ca. $55 \mathrm{~mm}$ compr., subulado a cilíndrico, ápice agudo, reto.

Material examinado: Itatiaia, 14.XI.2014, H. Dolsan \& M. Trovó 5 (RB).

Utricularia subulata possui distribuição praticamente Pantropical e, no Brasil, ocorre desde o Amazonas até o Rio Grande do Sul. (Taylor 1989; BFG 2015). Habita solos úmidos, arenosos, pântanos, margens de córregos e terrenos turfosos (Fromm-Trinta 1996). No Parque Nacional do Itatiaia foi encontrada no planalto próxima a um córrego em solo arenoso a turfoso, úmido. Utricularia subulata diferencia-se de U. gibba e $U$. praelonga pela presença de brácteas basolutas peltadas. Diferencia-se também de $U$. gibba por possuir folhas filiformes ao invés de lineares e ramificadas. Pode ser distinguida de $U$. praelonga também pela ausência de bractéolas, presença de brácteas com margens inteiras, ao invés de laciniadas e sépalas com lobos pouco diferenciados e margens inteiras, ao invés de desiguais e denteadas. No Parque Nacional do Itatiaia apresenta folhas mais longas e escapos mais curtos que o padrão da espécie. Floresce no mês de novembro.

\section{Utricularia tricolor A. St.-Hil., Voy. Distr. Diam.} 2: 418.1833.

Fig. 2d

Erva terrícola; folhas verdes, monomórficas, membranáceas, rosuladas na base do escapo, ou alternas folhas saindo do estolão, obovada a circular ou levemente reniforme, base atenuada a truncada, ápice arredondado, ca. $21 \times 17 \mathrm{~mm}$; pecíolo ca. 3,5 cm compr.; inflorescência ereta, simples, 1-2 flores; escapo terete, 16-20 cm compr., glabro, verde; escamas monomórficas, basifixas, deltoides, ápice agudo, margem inteira, ca. $13 \times 15 \mathrm{~mm}$ compr.; brácteas basifixas, rômbicas, ápice agudo ou acuminado, margem inteira, ca. $1 \mathrm{~mm}$ compr.; bractéolas presentes, fusionadas, similares as brácteas, porém menores e mais estreitas, lineares a subuladas; cálice com lobos desiguais, ovados, ápice agudo, margem crenada, lobo superior, ca. $5 \mathrm{~mm}$ compr.; lobo inferior, ca. 4 mm compr.; corola lilás ou violeta com mácula amarela e branca na giba; lábio superior largo elíptico, ápice arredondado, ca. $5 \times 2 \mathrm{~mm}$, maior que o cálice; lábio inferior transversalmente elíptico, ca. 10-20×10 mm, ápice arredondado e ligeiramente 3-crenado; calcar do mesmo comprimento ou levemente maior que o lábio inferior da corola, ca. $11 \mathrm{~mm}$ compr., cônico, ápice acuminado, reto a levemente curvado.

Material examinado selecionado: Itatiaia, 15.X.1992, M.G. Kuhlman (RB205135).
Material adicional selecionado: ESPÍRITO SANTO: 13.V.1949 A.C. Brade 19802 (RB); MINAS GERAIS: Bocaina, s.d., Mgf. et App. 10430 (RB); Poços de Caldas, s.d., M. Emmerich 2316 (RB); Serra do Cipó, s.d., P. Occhioni 4962 (RB); SANTA CATARINA: Florianópolis, XI.1971, P. Occhioni 4703 (RB).

Utricularia tricolor pode ser encontrada na Venezuela, Colômbia, Brasil, Bolívia, Paraguai, Uruguai e Argentina. No Brasil ocorre em todas as regiões (Taylor 1989; BFG 2015). Habita campos limpos próximo à mata de galeria ou veredas e campos de altitude (Souza \& Bove 2011). No Itatiaia é encontrada na parte alta do Parque. Pode ser diferenciada das outras espécies, principalmente de $U$. tridentata, pela corola com lábio inferior com ápice arredondado e ligeiramente 3-crenado, além de pedicelo curto. O nome Utricularia globulariifolia Mart. ex Benj., usado por Barroso (1957), está hoje na sinonímia de $U$. tricolor (Taylor 1989; BFG 2015). Floresce entre os meses de outubro e maio.

8. Utricularia tridentata Sylvén Ark. Bot. 8: 28. 1909.

Fig. 2e

Erva terrícola; folhas verdes, monomórficas, glabras, membranáceas, obovadas a circulares, base acuminada, ápice arredondado, ca. $2 \times 0,3$ $\mathrm{cm}$, pecíolo ca. $7 \mathrm{~mm}$ compr.; inflorescência ereta, simples, 1-3 flores; escapo terete, 7-14 cm compr., glabro, marrom; escamas monomórficas, basifixas, ovado-deltoides, margem inteira, ápice agudo, ca. $1 \mathrm{~mm}$ compr.; brácteas basifixas, deltoides, ápice acuminado, margem inteira, ca. 2,5 mm compr.; bractéolas presentes, fusionadas, lineares a subuladas ou oblanceoladas, do mesmo comprimento e mais estreitas que a as brácteas; cálice com lobos desiguais, glabro, ca. $3 \times 2$ $\mathrm{mm}$, margem inteira, lobo superior oblongo a ovado, ápice arredondado, lobo inferior menor, transversalmente elíptico, ápice emarginado; corola violeta ou lilás, com mancha amarela ou branca na base do lábio inferior; lábio superior ovado a oblongo, ápice arredondado, ca. 3× 1-2 mm; lábio inferior estreito-ovado, ápice arredondado, ca. 5-8 $\times 5 \mathrm{~mm}$ compr., distintamente 3-lobado; calcar ligeiramente mais comprido que o lábio inferior, ca. $11 \mathrm{~mm}$ compr., cônico, ápice obtuso, curvado. Material examinado selecionado: Itatiaia, 1937, A.C. Brade 15640 (RB); s.d., A.C. Brade 15642 (RB); V.1950, A.C. Brade 20329 (RB).

Material adicional selecionado: MINAS GERAIS: Serra do Cipó, 15.VI.1935, H.L.M. Barreto 1066 (RB).

Utricularia tridentata é endêmica da América do Sul, ocorrendo no Brasil, Uruguai e Argentina. No Brasil, a espécie ocorre apenas nos estados 
de Minas Gerais, Rio de Janeiro, Paraná, Santa Catarina e Rio Grande do Sul (BFG 2015). No entanto, a ocorrência dessa espécie no Sudeste do Brasil era discutível até recentemente (Taylor 1989). Ocorre preferencialmente em campos limpos, lagoas, pântanos, beiras de rio, em altitudes que variam geralmente de 1000-2000 m alt. (Taylor 1989). No parque foi encontrada na Lagoa do Altar e em rochedos do planalto do Itatiaia. Pode ser confundida com $U$. tricolor, porém diferencia desta e das demais espécies por possuir corola lilás com lábio inferior distintamente 3-lobado. Floresce entre novembro e fevereiro, podendo florescer também em maio.

\section{Agradecimentos}

Os autores agradecem à FAPERJ, o apoio financeiro dado ao Projeto Inventários da Flora Fluminense, uma abordagem interdisciplinar (E-26/110.031/2011, E-26/111.392/2012, E-26/010.001626/2014 - BIOTA) e também aos curadores dos herbários visitados. O terceiro autor agradece à Alexander von Humboldt Foundation, à UFRJ (ALV 2013), ao CNPq (proc. 470349/2013-1) e à FAPERJ (E-26/112.476 - INST). Agradecemos também a Fernando Rivadavia e a Paulo Minatel Gonella, o envio de imagens.

\section{Referências}

Andrade, B.S.C. \& Forzza, R.C. 2012. Lentibulariaceae no Parque Estadual do Ibitipoca, Minas Gerais, Brasil. Boletim de Botânica da Universidade de São Paulo 30: 23-35.

Aximoff, I. \& Ribeiro, K.T. 2012. Guia de plantas do Planalto do Itatiaia. Technical Books, Rio de Janeiro. $224 \mathrm{p}$.
Barroso, G.M. 1957. Flora do Itatiaia I: Lentibulariaceae. Rodriguésia 32: 136-137.

BFG. 2015. Growing knowledge: an overview of seed plant diversity in Brazil. Rodriguésia 66: 1085-1113.

Blanca, G.; Ruiz-Rejón, M. \& Zamora, R. 1999. Taxonomic revision of the genus Pinguicula L. in the Iberian Peninsula. Folia Geobotanica 34: 337-361.

Câmara, I.G. 1991. Plano de ação para a Mata Atlântica. Fundação SOS Mata Atlântica, São Paulo. 40p.

Casper, S.J. 1996. Monographie der Gattung Pinguicula. Bibliotheca Botanica 127/128: 71-76.

Fleischmann, A. 2012. Monograph of the genus Genlisea. Redfern Natural History Productions Ltd., Poole. $727 \mathrm{p}$.

Fromm-Trinta, E. 1979. Revisão das espécies do gênero Genlisea A.St.Hil. (Lentibulariaceae) das regiões Sudeste e Sul do Brasil. Rodriguésia 31: 17-139.

Fromm-Trinta, E. 1996. Flora da Serra do Cipó, Minas Gerais: Lentibulariaceae. Boletim de Botânica da Universidade de São Paulo 15: 106-118.

Fromm-Trinta, E. 2004. Flora de Grão-Mogol, Minas Gerais: Lentibulariaceae. Boletim de Botânica da Universidade de São Paulo 22: 267-271.

Pádua, M.T.J. \& Coimbra-Filho, A.F. 1979. Os parques nacionais do Brasil. Instituto Brasileiro de Desenvolvimento Florestal, Brasília. 224p.

Salimena, F.R.G.; Matozinhos, C.N.; Abreu, N.J.; Ribeiro, J.H.C.; Souza, F.S. \& Menini Neto, L. 2013. Flora Fanerogâmica da Serra Negra, Minas Gerais, Brasil. Rodriguésia 64: 311-320.

Silva, N.G.; Alves, R.J.V.; Fontella, J.P. \& Rivadavia, F. 2011. Lentibulariaceae, Serra de São José, Minas Gerais, Brazil. Checklist 7: 120-127.

Souza, P.C.B. \& Bove, C.P. 2011. Flora dos estados de Goiás e Tocantins - Lentibulariaceae (42). Editora da Universidade Federal de Goiás, Goiânia. 136p.

Taylor, P. 1989. The genus Utricularia - a taxonomic monograph. Kew Bulletin Additional Series XIV, London. $724 \mathrm{p}$.

\section{Lista de exsicatas}

Barreto, H.L.M. 1066a - RB (7). Brade, A.C. 14644 - RB (2). Brade, A.C. 15144 - RB. Brade, A.C. 15145 - RB (4). Brade, A.C. 15640 - RB (7). Brade, A.C. 15641 - RB (4). Brade, A.C. 15642 - RB (7). Brade, A.C. 15643 - RB (1). Brade, A.C. 15646 - R (1). Brade, A.C. 19802 - RB (8). Brade, A.C. 20226 - RB (4). Brade, A.C. 20329 - RB (7). Braga, J.M.A. 1419 - RB (5). Couto 318 - RFA (1). Dudziak, C. 37 - R (3). Esteves, F.A. 33 - RFA (2). Forzza, R.C 2658 - RB (3). Forzza, R.C. 3915 - RB (3). Forzza, R.C. 7317 - RB (2). Guedes, A. 1 - RFA (1). Kaempfe - RB (5). Kuhlman, J.G. - RB (3). Kuhlman, J.G. - RB (8). Lute, B. 1303 - R (2).Lutz, A. 1231 - RB (5). Maas, P.J.M. 3180 - RB (5). Mansano, V.F. 192 - RB (5). Martinelli, G. 7764 - RB (5). Mello-Silva, R. 3065 - RB (3). Emmerich, M. 2316 - R (8). Mgf. et App. 10430 - RB (8). Monteiro, R.F. 68 - RB (5). Moreira, C. 42 - R (2). Mynssen, C.M. 1206 - RB (5). Occhioni, P. 915 - RFA (5). Occhioni, P. 2050 - RFA (1). Occhioni, P. 4703 - RFA (8). Occhioni, P. 4962 - RFA (8). Occhioni, P. 7678 - RFA (2). Occhioni, P. 8776 - RFA (2). Occhioni, P. 948 - RFA (5). Porto, P.C. 997 - RB (4). Sick, H. 208 - RB (4). Silva Neto, S.J. 1178 - RB (5). Silva Neto, S.J. 1740 - RB (5). Silva Neto, S.J. 754 - RB (5). Smith, L.B. 1964 - RFA (5). Sucre, D. 4674 - RB (5). Ule, E. 216 - R(2). Ule, E. 1575 - R (1). Vianna, F.S. 770 - RFA (4). Vianna, F.S. 758 - RFA (5). Viela, M.L. 21 - RB (5). Zappi, D.C. 1868 - RB (3). 